\title{
Las tecnologías en la enseñanza de las ciencias: los retos de los docentes corregentes de los primeros grados
}

\author{
Juciele Gemin Loeper \\ igloeper@gmail.com \\ https://orcid.org/0000-0001-7145-2491 \\ Sérgio Camargo \\ s1.camargo@gmail.com \\ https://orcid.org/0000-0001-8766-5424
}

Universidade Federal do Paraná (UFPR, Brasil)

Recibido: 31/05/2020 Aceptado: 25/07/2020

\begin{abstract}
Resumen
Este artículo presenta el resultado de una investigación cualitativa realizada con los auxiliares docentes de los primeros grados en el ámbito de las escuelas del Municipio de Curitiba, con el objetivo de analizar los retos que enfrentan los docentes corregentes de los primeros grados con las tecnologías. Como instrumentos para la constitución de los datos se utilizaron cuestionarios, entrevistas, prácticas pedagógicas, así como el material oficial de orientación del currículo de la educación primaria, los proyectos político-pedagógicos y la normativa de las escuelas participantes. El análisis de datos se realizó mediante el análisis de contenidos con la ayuda del software Atlas.Ti. En los resultados se señalan tres factores: 1) los individuales; la tecnología entendida y asociada solo como un apoyo en la enseñanza-aprendizaje, 2) institucionales; el ambiente escolar es obsoleto y necesita reciclarse para acompañar los cambios tecnológicos, renovando y actualizando su equipamiento, y 3) factores documentales; la necesidad de la difusión entre la teoría y la práctica, que los docentes participen en la elaboración, no siendo solo una lista de contenidos impuestos y restringidos a la dirección de la escuela o al personal técnico. Se puede concluir que, aun viviendo tiempos de cambios y desafíos diarios, el docente, como agente transformador influenciado por este movimiento, enfrenta y enfrentará muchos desafíos individuales, institucionales y documentales si quiere seguir este proceso y actualizarse, innovar y mejorar su práctica pedagógica frente a las tecnologías.
\end{abstract}

Palabras clave: Enseñanza de la Ciencias; Tecnología; Primeros años de escolaridad.

\section{As tecnologias no ensino de ciências: os desafios dos Professores corregentes dos anos iniciais}

\begin{abstract}
Resumo
Este artigo apresenta o resultado de uma pesquisa qualitativa desenvolvida junto aos professores corregentes dos anos iniciais no âmbito das escolas do Município de Curitiba, tendo como objetivo analisar os desafios pelos quais os professores corregentes dos anos iniciais passam frente às tecnologias. Como instrumentos para a constituição dos dados foram usadas questionários, entrevistas, práticas pedagógicas, bem como o documento oficial norteador currículo do ensino fundamental, os projetos político-pedagógicos e os regimentos das escolas participantes. A análise dos dados foi realizada por meio da análise de conteúdos com o auxílio do software Atlas.Ti. Nos resultados três fatores são apontados:
\end{abstract}


1) os individuais a tecnologia entendida e associada apenas como um apoio no ensinoaprendizagem; 2) institucionais o ambiente escolar está obsoleto e precisa acompanhar as mudanças tecnológicas, renovando e atualizando seus equipamentos, e 3) fatores documentais a necessidade da difusão entre a teoria e prática, que ocorra a participação dos professores na elaboração, não sendo apenas um rol de conteúdos impostos e restritos à gestão escolar ou equipe técnica É possível concluir que mesmo vivenciando tempos de mudanças e desafios cotidianos, o professor, como agente transformador influenciado por esse movimento, enfrenta e enfrentará muitos desafios individuais, institucionais e documentais se quiserem acompanhar esse processo e se atualizar, inovar e aprimorar a sua prática pedagógica frente às tecnologias.

Palavras-chave: Ciências; Tecnologia; Anos Iniciais.

\title{
The technologies in the teaching of sciences: The challenges of the teachers of the initial years
}

\begin{abstract}
This article presents the result of a qualitative research developed with the corregent teachers of the initial years in the scope of the schools of the Municipality of Curitiba, with the objective of analyzing the challenges that the corregent teachers of the initial years face with the technologies. As instruments for the constitution of the data, questionnaires, interviews, pedagogical practices were used, as well as the official document guiding the curriculum of elementary education, the political-pedagogical projects and the regulations of the participating schools. Data analysis was performed through content analysis with the aid of the Atlas.Ti software. In the results, three factors are pointed out: 1) the individual the technology understood and associated only as a support in teaching-learning, 2) institutional the school environment is obsolete and needs to keep up with technological changes, renewing and updating its equipment, and 3) documentary factors the need for diffusion between theory and practice, for teachers to participate in the elaboration, not just being a list of imposed and restricted contents to school management or technical staff It is possible to conclude that even experiencing times of change and daily challenges, the teacher, as a transforming agent influenced by this movement, faces and will face many individual, institutional and documentary challenges if they want to follow this process and update themselves, innovate and improve your pedagogical practice in the face of technologies.
\end{abstract}

Keywords: Science; Technology; Early Years.

\section{Introdução}

A tecnologia cada vez mais presente na sociedade faz com que a comunidade escolar busque possíveis mudanças junto à evolução tecnológica, não apenas superficialmente, mas engajados em prol do ensino-aprendizagem ${ }^{1}$.

\footnotetext{
1 Optamos por utilizar ensino-aprendizagem e projeto político-pedagógico conforme utilizado por Vasconcellos (2010).
} 
Dados estatísticos mostram que o acesso e uso das Tecnologias de Informação e Comunicação (TIC) fornecidos pelo Comitê Gestor da Internet no Brasil (CGI.br), no ano de 2016, 95\% das escolas públicas e 98\% das escolas particulares localizadas em áreas urbanas tinham ao menos um tipo de computador com conexão à internet. $\mathrm{O}$ uso da internet em sala de aula apresentou também uma variação positiva em 2016, especialmente nas escolas públicas, passando de $43 \%$ para $55 \%$.

Na capital Curitiba, conforme dados do Departamento de Planejamento, Estrutura e Informação (DPEI) da Secretaria Municipal da Educação (SME) ${ }^{2}$ no ano 2018, as escolas da Rede Municipal de Ensino (RME) possuem televisão, rádio, laboratório de informática com computadores conectados à internet, notebooks e projetor multimídia. Ou seja, os professores vivenciam em seu cotidiano as provocações e os desafios proporcionados pelo aumento do ritmo da evolução tecnológica, e por estudantes ativos no uso dessas tecnologias.

As tecnologias já estão nas escolas e cada professor estabelece uma relação particular com elas em sua prática pedagógica, influenciada pelos múltiplos fatores que configuram esse processo e sua concepção ao interagir permanentemente com as dimensões histórica, social, cultural e política.

O conceito de tecnologia adotado na pesquisa fundamenta-se em Brito (2006, p. 8) "o termo tecnologia vai muito além de meros equipamentos permeia em toda a nossa vida, inclusive em questões não tangíveis. Classificadas em três grandes grupos: física, organizadora e simbólica (Sancho, 1998).

Tecnologias físicas são as inovações de instrumentais físicos, como: caneta esferográfica, livro, telefone, aparelho celular, satélites, computadores (ou seja, equipamentos); estão relacionadas com a Física, Química, Biologia, etc. A tecnologia física muitas vezes é entendida como produto e não como processo, isso pode levá-la a transformar-se apenas num fim e não em meio. Já tecnologias organizadoras são as formas como nos relacionamos com o mundo, como os diversos sistemas produtivos estão organizados: sociedade, currículo, projeto político-pedagógico e plano de aula.

\footnotetext{
2 Secretaria Municipal da Educação. Departamento de Estrutura e Informação: https://educacao.curitiba.pr.gov.br/
} 
Tecnologias simbólicas estão relacionadas com a forma de comunicação entre as pessoas, desde a iniciação dos idiomas escritos e falados até a forma como se comunicam. São os símbolos de comunicação e interfaces de comunicação.

A partir do conceito de tecnologia organizadora temos como exemplo, toda a forma como a escola é organizada; como os programas e currículos são estruturados; como os professores, planejam, elaboram e executam suas aulas. Já com o conceito de tecnologia simbólica temos, por exemplo, toda a comunicação que ocorre em uma aula, seja ela entre professor e alunos, alunos e alunos, professor e conhecimento, alunos e conhecimentos e principalmente como cada um e todos juntamente se comunicam (Simonian, 2016, p.51).

Segundo Brito (2006), por meio de uma pesquisa realizada com professores, alguns entrevistados não apontaram para nenhum dos conceitos acima. $\mathrm{Na}$ verdade, eles se referiram às tecnologias educacionais como:

Recursos que usamos com nossos alunos para proporcionar conhecimento, que vão desde a nossa exposição oral/dialogada ao uso do computador que está ligado ao mundo do conhecimento. As tecnologias (livro, vídeo, computador, rádio...) propiciam novas formas de aprender, ensinar e produzir conhecimento e são utilizadas de acordo com os propósitos educacionais, bem como, as estratégias mais adequadas à aprendizagem. (Brito, 2006, p.12).

Além das tecnologias educacionais, os entrevistados também citam a tecnologia social, descrevendo-a como "conjunto de invenções, técnicas etc., para transformar algo e que é desenvolvida juntamente com a população e será utilizada por ela, por exemplo uma rádio comunitária" (Brito, 2006, p. 14).

Gomes (2018), a partir de definições de Brito (2006), refere-se à tecnologia educacional como artefatos que fazem parte da realidade escolar, utilizados no processo de ensino e aprendizagem, abrangendo desde o retroprojetor até o livro e o computador. O que caracteriza um recurso tecnológico como educacional é o fato de seu uso ser planejado, contextualizado e significativo do ponto de vista educacional.

Essas categorias estão interligadas e que esta classificação visa apenas facilitar a compreensão do conceito mais amplo de tecnologia, entendido como conhecimento científico aplicado, considerado o processo e não somente o produto, conforme ressaltam Brito (2006) e Gomes (2013), com base em Sancho (1988).

Nesta perspectiva questiona-se: Quais são os desafios dos professores frente às tecnologias nas suas práticas pedagógicas? Para alcançar o objetivo geral quanto à análise 
dos desafios dos professores corregentes dos anos iniciais do ensino fundamental, no ensino de ciências frente às tecnologias, traçamos objetivos específicos, que balizaram a pesquisa, usando diferentes instrumentos (questionários, entrevistas e documentos norteadores) para analisar como as tecnologias estão empregadas nos documentos oficiais norteadores dos anos iniciais da Secretaria Municipal da Educação de Curitiba e identificar os principais desafios encontrados pelos professores corregentes dos anos iniciais, na prática pedagógica no componente curricular de ciências.

A atuação dos professores passa por reconfigurações diante das tecnologias no processo de ensino-aprendizagem, como grande desafio de articular e preparar as gerações que já estão conectadas "utilizar as tecnologias digitais é uma maneira de nos aproximarmos da geração que está em nossas escolas" (Curitiba, 2016, p. 41). Tão importante quanto conhecer as tecnologias é saber como promover e desencadear a integração na prática pedagógica, por meio de estratégias e metodologias que considerem a tecnologia como elemento diferenciado e diferenciador nas atividades escolares, estimulando a reflexão dos estudantes ${ }^{3}$. Entendemos por prática pedagógica não apenas o trabalho com estudantes, mas o ato de planejamento de aulas, as permanências ${ }^{4}$, os encaminhamentos didático-metodológicos de preparação de materiais e o estudo do professor.

\section{As tecnologias na prática pedagógica no ensino de ciências dos anos iniciais}

Os ambientes educacionais no Ensino Fundamental I (1. ${ }^{\circ}$ ao $5 .^{\circ}$ ano) do município de Curitiba contam com profissionais concursados para o cargo de Profissional do Magistério com a mesma formação, nas escolas são organizados como regentes, corregentes e de permanência, Os regentes lecionam os componentes curriculares Língua Portuguesa, Matemática, História e Geografia; os professores de permanência lecionam Arte, Ensino Religioso e Educação Física e os corregentes que trabalham em parceria com dois regentes por meio do trio de regência ${ }^{5}$, lecionam duas aulas semanais do componente

\footnotetext{
3 Decidimos por utilizar o termo estudante por entendermos que é o termo mais abrangente. Porém, trataremos de alunos quando direcionado à modalidade do ensino fundamental, como seu sinônimo.

4 A permanência é o espaço da carga horária semanal destinada aos professores para que participem de estudo, planejamento, avaliação em cursos e atendimento às famílias. É o momento privilegiado de trabalho coletivo entre docentes, organizado e articulado pela equipe pedagógica, de forma a promover a reflexão e tomada de decisões sobre o processo ensino-aprendizagem. (Instrução Normativa n. ${ }^{\circ} 13 / 2013$ )

${ }^{5}$ Organização relativamente nova, oficialmente a partir de 2014. Portaria n. ${ }^{\circ}$ 45/2014 - Disponível em: http://www.educacao.curitiba.pr.gov.br/conteudo/legislacao-basica/4883.
} 
curricular ciências e também atua com os alunos que apresentam maior dificuldade na aprendizagem, ou seja, para cada dois regentes há um corregente.

A escolha de pesquisar os corregentes se dá pelo fato de eles trabalharem quase que exclusivamente com ciências, supondo uma valorização do componente curricular, já que esses professores planejam exclusivamente essas aulas.

O ensino das Ciências da Natureza é de grande valia no currículo escolar, pois "não se trata somente de ensinar a ler e a escrever para que os estudantes possam aprender Ciências, mas também fazer uso das Ciências para que os estudantes possam aprender a ler e a escrever" (Brasil, 1998, p.62).

Segundo Fumagalli (1998), justifica-se o trabalho com Ciências nos anos iniciais por três motivos: o direito das crianças de aprender Ciências; o dever social obrigatório da escola em difundir conhecimentos científicos à população, e o valor social do conhecimento científico. A autora afirma ainda que não ensinar Ciências nos anos iniciais, sob o argumento que as crianças não têm capacidades intelectuais, é uma forma de discriminá-las como sujeitos sociais.

No currículo do Ensino Fundamental, as ciências naturais é o componente curricular que objetiva estudar as relações entre a ciência, a tecnologia, o ser humano e o restante da natureza. Nesse componente, estão contempladas as ciências biológicas, físicas e químicas, além da astronomia, as geociências, a anatomia e a fisiologia, entre outras consideradas ciências da natureza.

Compreendemos a Ciência como uma atividade humana, social e historicamente construída, cuja finalidade é produzir conhecimentos de forma sistemática e passíveis de verificação, que contribuam para o entendimento da realidade. A produção da Ciência não se faz de forma neutra, cumulativa e linear, pois está sujeita à influência de fatores políticos, econômicos e culturais de cada época. (Curitiba, 2016, p. 05).

Esse conhecimento é disponibilizado com a finalidade de proporcionar uma cultura científica que permita aos estudantes compreender o funcionamento da natureza e a influência dos avanços científicos e tecnológicos na vida social das pessoas. Delizoicov e Slongo (2011) ao tecer considerações sobre as razões de ensinar Ciências nos anos iniciais do Ensino Fundamental citam Fracalanza et al. (1986), sobre o que é esperado do ensino de ciências: 
O ensino de ciências, entre outros aspectos, deve contribuir para o domínio das técnicas de leitura e escrita; permitir o aprendizado dos conceitos básicos das ciências naturais e da aplicação dos princípios aprendidos a situações práticas; possibilitar a compreensão das relações entre a ciência e a sociedade e dos mecanismos de produção e apropriação dos conhecimentos científicos e tecnológicos; garantir a transmissão e a sistematização dos saberes e da cultura regional e local. (Fracalanza et al., 1986, p. 26-27).

Delizoicov e Slongo (2011, p. 209) afirmam que, "antes mesmo de chegar à escola, a criança já realizou um significativo percurso, explorando seu entorno. O ensino de Ciências nessa faixa escolar deve oportunizar à criança explorar o mundo natural e social no qual está inserida".

Para os autores, o ensino de Ciências torna-se relevante, "pois possibilita ao aluno uma participação ativa no processo de apropriação do conhecimento" bem como "o ensino de Ciências para alunos de pouca idade tem uma dimensão lúdica, a qual deve ser preservada sem que haja prejuízo em termos de conteúdo, o objetivo é que o conhecimento científico não seja imposto e sim, desejado” (Delizoicov e Slongo, 2011. p. 209).

Para se alcançar o objetivo com estudantes dos anos iniciais da RME, segundo o documento Currículo do Ensino Fundamental, a área de ciências da natureza precisa de uma primeira aproximação das noções de ambiente, fenômenos celestes, corpo humano e transformações de materiais do ambiente por meio de técnicas inventadas pelo ser humano. Os estudantes podem aprender procedimentos simples de observação, comparação, busca e registro de informações, e também desenvolver atitudes de responsabilidade para com o próprio corpo, com o outro e com o ambiente.

No documento, também defende que o contexto social atual requer novas maneiras de ensinar, aprender e desenvolver o currículo em um mundo cada vez mais globalizado e "utilizar as tecnologias digitais é uma maneira de nos aproximarmos da geração que está em nossas escolas" (Curitiba, 2016, p. 41), refletindo sobre a importância e influência das tecnologias para a sociedade, citando Krasilchik (1988):

O avanço da Ciência está intrinsecamente relacionado ao desenvolvimento de novas tecnologias, e esta relação influencia o dia a dia de cada cidadão(ã) e exige a análise das implicações sociais do desenvolvimento científico e tecnológico. (Curitiba, 2016, p. 75)

Além disso, no documento, evidenciam-se as tecnologias como um processo contínuo da sociedade através do qual a: 
[...] humanidade molda, modifica e gera a sua qualidade de vida. Há uma constante necessidade do ser humano de criar, a sua capacidade de interagir com a natureza, produzindo instrumentos desde os mais primitivos até os mais modernos, utilizando-se de um conhecimento científico para aplicar a técnica e modificar, melhorar, aprimorar os produtos oriundos do processo de interação deste com a natureza e com os demais seres humanos. (Curitiba, 2016, p. 40)

A velocidade das inovações precisa ser compreendida em suas múltiplas dimensões: econômicas, políticas, técnicas, culturais, educacionais etc. Apontando desafios em nossa forma de pensar, de conhecer e de aprender. Cada professor estabelece uma relação particular com as tecnologias em sua prática pedagógica, influenciada pelos múltiplos fatores que configuram esse processo e sua concepção ao interagir permanentemente com as dimensões histórica, social, cultural e política. A prática pedagógica é construída ao longo do seu percurso profissional, das experiências, de sua história de vida e de seus aprendizados, de suas relações em grupo, na escola e na sociedade, inter-relacionando-se à profissão docente.

Assim, o processo educacional deve caminhar aliado à evolução tecnológica não apenas superficialmente, mas engajado em prol de resultados efetivos na prática pedagógica. Deve-se salientar que:

A tecnologia é vista como um catalisador e uma ferramenta que reativa a empolgação do professor e dos alunos pelo aprender e que torna a aprendizagem mais relevante ao século XXI. Mas a tecnologia não é somente um ingrediente nos esforços de reforma. A tecnologia é utilizada de forma mais poderosa como uma nova ferramenta para apoiar a indagação, composição, colaboração e comunicação. (Ringstaff, et ál., 1997, p. 23)

Camas (2012), baseada nas experiências dos pesquisadores Ringstaff et al. (1997), aponta a necessidade de formar e expor o professor às tecnologias de sua época para que aprenda a usá-la. Assim, passa a conhecer e ter a opção de adotar a tecnologia que melhor convém às habilidades e às necessidades de seus objetivos de aula. Em seguida desse uso inicial, é feita a transição do adaptar, entendida como a ação de aprimorar algo com as tecnologias adotadas, tendo o propósito de fazer melhor aquilo que já se fazia sem as tecnologias. Caminha-se, dessa forma, para apropriação das tecnologias, de modo que haja autonomia de uso a ponto de integrar a sua prática cotidiana as tecnologias adotadas, para uma determinada finalidade de ensino e aprendizagem.

Após essa apropriação, acontece a instauração do senso crítico no uso significativo: autonomia da escolha da melhor ferramenta para um melhor processo educacional, gerando o inovar: "que é a perspectiva final da inserção das tecnologias na escola, na transformação e mudança na prática pedagógica” (Camas, 2012, p. 55). 
Há, portanto, um ciclo de apropriação de Ringstaff (1997), citado por Camas (2012): exposição, adoção, adaptação, apropriação e inovação, visando à integração curricular das tecnologias nas práticas pedagógicas.

Com isso, o professor se posiciona como um parceiro, caminhando e orientando o estudante para as tantas possibilidades e formas de adquirir conhecimento e também de como estabelecer respectivas relações (Kenski, 2007). Ensinar, portanto, "envolve uma disponibilidade para lidar com o outro e compreendê-lo. Envolve gosto e identificação com a docência. Ensinar pressupõe construção do conhecimento [...]”. (Veiga, 2006, p. 24-25).

É nesse viés que a pesquisa caminhou para analisar e identificar os desafios encontrados pelos professores corregentes, na prática pedagógica do componente curricular de ciências em relação às tecnologias.

\section{A pesquisa}

Esta pesquisa é de natureza qualitativa com base em Ludke e André (1986), “[...] para se realizar uma pesquisa é preciso promover o confronto entre os dados, as evidências, as informações coletadas sobre determinado assunto e o conhecimento teórico acumulado a respeito dele.” (Lüdke \& André 1986, p. 1).

Desenvolvida junto aos professores corregentes dos anos iniciais no âmbito das escolas da Rede Municipal de Ensino de Curitiba. Com o objetivo central de analisar os desafios pelos quais os professores corregentes dos anos iniciais do Ensino Fundamental passam frente às tecnologias, no ensino de Ciências. Para tanto, foram utilizados diferentes instrumentos:

- Questionário previamente estruturado: para delimitar o campo a ser pesquisado e os professores a serem investigados, a partir de critérios de inclusão e exclusão.

- Entrevistas semiestruturadas: para analisar a trajetória de cada participante frente ao objetivo central.

- Encaminhamento didático-metodológico, ou seja, uma prática pedagógica, escolhida pelo próprio professor: para identificar as tecnologias.

- Documentos na Rede Municipal de Ensino de Curitiba: a) Currículo do Ensino Fundamental, b) Projeto Político-Pedagógico e c) Regimento Escolar das escolas participantes: para analisar como as tecnologias estão empregadas nos documentos oficiais norteadores da RME. 


\section{A propósito do questionário para delimitar o campo de pesquisa}

No início da pesquisa, a primeira iniciativa, foi solicitada à Secretaria Municipal da Educação (SME), por meio do Departamento do Ensino Fundamental (DEF), autorização para enviar questionário às escolas municipais da Rede Municipal de Curitiba. Após a aprovação, a pesquisadora requereu ao Departamento de Planejamento, Estrutura e Informação (DPEI) informações sobre a quantidade de professores corregente atuantes no componente curricular de ciências, sendo um total de 2.861 professores.

Para atingir essa totalidade foi elaborado o questionário online, visto que o foco da pesquisa envolve as tecnologias, com um link sendo enviado via correio eletrônico, no dia 20 de outubro de 2017, às 185 escolas municipais solicitando a participação dos professores corregentes dedicados ao ensino do componente curricular ciências.

O questionário foi moderado em 3 blocos de perguntas: No primeiro, buscou obter informações para delimitar a participação, com critérios de inclusão e exclusão.

\section{Critérios de inclusão}

- Professor(a) atuante com o componente curricular de ciências.

- Professor(a) do Ensino Fundamental I (1. ${ }^{\circ}$ ao $5 .^{\circ}$ ano).

- Disponibilidade para entrevista.

- Disponibilidade para enviar uma prática pedagógica.

\section{Critérios de exclusão}

- Respostas duplicadas.

- Professor(a) não atuante com o componente curricular de ciências.

- Professor(a) não atuante no Ensino Fundamental I (1. ${ }^{\circ}$ ao 5. ${ }^{\circ}$ ano).

- Indisponibilidade para entrevista.

- Indisponibilidade para enviar uma prática pedagógica.

No segundo bloco, foi questionado o conhecimento dos documentos norteadores. E as últimas perguntas foram referentes às tecnologias: na vida pessoal, na prática pedagógica e na infraestrutura da escola. 


\section{Organizando as entrevistas com os professores}

Em um segundo momento da pesquisa, optamos por realizar a entrevista, que é "uma das principais técnicas de trabalho em quase todos os tipos de pesquisa utilizados nas ciências sociais" (Lüdke \& André, 2015, p. 38) para identificar e analisar os principais desafios encontrados pelos professores corregentes dos anos iniciais na prática pedagógica do componente curricular de ciências, frente às tecnologias.

Foi utilizada a entrevista semiestruturada online, visto que o foco envolve tecnologias, com auxílio do site Appear ${ }^{6}$, que funciona por salas (rooms). As entrevistas foram realizadas online e gravadas com o auxílio do sotware OBS Studio ${ }^{7}$ e um gravador portátil. Foram preparadas cuidadosamente: conferência dos equipamentos e da conexão com antecedência, microfone sem interferência, webcam bem focada, local apropriado e sem ruídos, adequadamente iluminado, com fundo branco e programado para não ter interrupções.

Primeiramente, as videoentrevistas foram agendadas para os horários de permanência ou hora-atividade das professoras, porém 100\% das escolas não ofereceram conexão com a internet suficiente para realização da videoentrevista. Somente 02 foram realizadas na escola, usando o celular e a internet (dados móveis) da própria professora e 11 professoras reagendaram os horários, remarcando para o período noturno nas suas residências. Com o auxílio do Express $\mathrm{Scribe}^{8}$, as videoentrevista foram transcritas, seguindo as normas de Preti (1999, p.11 e p.12).

A construção da textualização começou com a identificação de traços comuns que permitiram classificar a correção, em que foram retiradas palavras repetidas como: eh, né, assim, tá, ah. Para Preti (1999, p.134), “a correção é um procedimento de reelaboração do discurso que visa a consertar seus "erros". O "erro" deve ser entendido como escolha do falante, ele ou seu interlocutor consideram inadequada”. Mantivemos as gírias, pensamentos, inadequações de coerências/concordâncias, pois "fazem parte de sua

\footnotetext{
${ }^{6}$ Appear.in: programa online e gratuito que permite videoconferências de computador a computador sem baixar nenhum software instalado. Disponível em: http://br.ccm.net/faq/16796-appear-in-videoconferenciasem-instalar-nenhum-software. Acesso em: 31/05/2020.

${ }^{7}$ OBS Studio: software é um programa gratuito e livre de uso para quem deseja transmitir e gravar vídeo ao vivo na Internet. Disponível em: https://obsproject.com/pt-br/download. Acesso em: 31/05/2020.

8 Express Scrib: software para auxiliar na transcrição de áudio auxiliando a digitação Disponível em: http://www.expressscribe.com.br/ Acesso em: 31/05/2020.
} 
organização persuasivo argumentativo e de sua estruturação", conforme Preti (1999, p.155).

A textualização foi enviada por e-mail às 13 professoras para aprovação, informando que na pesquisa há a garantia da confidencialidade do sujeito e que os dados obtidos são utilizados apenas para fins científicos. Após aprovação, as respostas foram renomeadas e exportadas para o software Atlas.Ti, para auxiliar no processo de descrição e análise dos dados.

\section{Sobre as práticas pedagógicas dos professores}

Aos participantes da pesquisa foi solicitado um plano de aula, de escolha do professor no qual tenha integrado as tecnologias, considerando: o conteúdo curricular trabalhado, o recurso utilizado e o processo de desenvolvimento didático da aula (início/meio/fim). No total, recebemos trinta e quatro planos de aula, que foram organizados por ano/ciclo.

Quadro 1: Planos de aula recebidos por ano/ciclo

\begin{tabular}{|c|c|}
\hline Ano/ciclo & Quantidade práticas pedagógicas recebidas \\
\hline 1 ano - ciclo $\mathrm{i}$ & 4 \\
\hline \multirow[t]{4}{*}{$2^{\circ}$ ano - ciclo $i$} & 1 \\
\hline & 1 \\
\hline & 5 \\
\hline & 4 \\
\hline \multirow[t]{3}{*}{$3^{\circ}$ ano - ciclo i } & 3 \\
\hline & 1 \\
\hline & 1 \\
\hline \multirow[t]{3}{*}{$4^{\circ}$ ano - ciclo ii } & 4 \\
\hline & 3 \\
\hline & 2 \\
\hline \multirow[t]{2}{*}{$5^{\circ}$ ano - ciclo ii } & 1 \\
\hline & 4 \\
\hline \multicolumn{2}{|c|}{ Total 34} \\
\hline
\end{tabular}

Fonte: Loeper e Camargo (2018)

De posse dos planos de aula, conforme o quadro 1, identificamos uma disparidade na quantidade de práticas pedagógicas recebidas para a pesquisa, para o $1^{\circ}$ ano recebemos 4 (quatro), já para o $2^{\circ}$ ano recebemos 11 (onze) práticas pedagógica, então, foram reorganizadas por data e separado apenas um plano de aula por professor, o último enviado, com a data mais recente. 


\section{A respeito dos documentos oficiais norteadores}

Os documentos oficiais norteadores da Secretaria Municipal da Educação referem-se às leis, diretrizes que regulamentam todas as ações para que haja um padrão a ser seguido. Para analisar como as tecnologias estão empregadas, usamos:

a) Currículo do Ensino Fundamental.

b) Projeto Político-Pedagógico (PPP).

c) Regimento Escolar (RE)-

O Currículo do Ensino Fundamental é a diretriz vigente para todas as escolas da RME, e tem como finalidade nortear a prática pedagógica dos professores, apresentando conteúdos, objetivos e critérios de avaliação desenvolvidos por ciclos e etapas do Ensino Fundamental, além dos princípios para a educação. Está disponível para download no site da $\mathrm{SME}^{9}$. Para esta pesquisa, foram baixados em formato PDF os dados do Volume I Princípios e Fundamentos e do Volume IV - Área Ciências da Natureza.

O Projeto Político-Pedagógico e o Regimento Escolar das 11 escolas participantes não foram encontrados na página educacional de cada unidade ${ }^{10}$. Então foram solicitados a Secretaria Municipal da Educação de Curitiba.

\section{O software Atlas.Ti}

O uso do software Atlas.Ti é indicado para análise em que se usam instrumentos diversos e complementares, e tem como principal objetivo ajudar a organizar, registrar e possibilitar o acompanhamento dos registros efetuados, contribuindo para a confiabilidade do estudo. De acordo com Vosgerau, Pocrifka e Simonian (2016), atualmente as possibilidades de uso do software Atlas.Ti têm sido amplamente discutidas sob diversas perspectivas.

O software permite algumas vantagens em relação a técnicas antigas empregadas na análise de conteúdo. É possível realizar anotações e comentários, elaboração de relatórios, de memorandos, edição, disposição de dados em tabelas e matrizes, entre outros.

${ }^{9}$ Disponível em: http://www.educacao.curitiba.pr.gov.br/conteudo/curriculo/8388. Acesso em: 24/01/2019.

${ }^{10}$ Disponível em: https://educacao.curitiba.pr.gov.br/unidades/. Acesso em: 31/05/2020. 
Este software foi elaborado pelo pesquisador alemão Muhr $(1994 ; 2016)$ em um projeto de pesquisa na Technical University of Berlin (1994), sendo que sua estrutura se baseia na Teoria Fundamentada (Grounded Theory) e codificação teórica de Strauss (1987), e ao longo de mais de 20 anos tem sido aprimorado e utilizado por diferentes universidades e institutos de pesquisa (Flick, 2009). (Vosgerau et al., 2016, p.95)

Tanto Saldaña (2016) quanto Bardin (2011) recomendam a utilização de Qualitative Data Analysis Software (QDAS), desde que o pesquisador já esteja familiarizado com suas funcionalidades e domine as técnicas da codificação em ciclos ou análise de conteúdo.

Para Bardin (2011) o uso de software na análise de conteúdo apresenta vantagens como: rapidez, maior rigor na organização da investigação, flexibilidade sobre a inferência dos dados, maior facilidade para reproduzir e trocar documentos, e manipular dados complexos, assim como permite maior criatividade por parte do pesquisador.

A pesquisadora principal desta pesquisa realizou a compra com recursos próprios da Student License diretamente no site da empresa Atlas.Ti do referido software. Sua escolha em detrimentos dos demais Qualitative Data Analysis Software (QDAS) se deu pelo conhecimento de sua utilização já na pesquisa de pós-graduação, bem como pelo fato deste permitir um trabalho longitudinal com os dados.

\section{Metodologia de análise e organização dos dados}

Quando realizamos uma pesquisa é preciso promover o confronto entre os dados, as evidências, as informações coletadas sobre determinado assunto e o conhecimento teórico acumulado a respeito dele" (Lüdke \& André, 1986, p. 1). Neste sentido, utilizou a análise de conteúdo para descrever não somente a mensagem (informação) obtida, mas o questionamento das causas e efeitos da mensagem, sendo uma técnica que exige rigor e pode ser aplicada em qualquer área e com diferentes fontes de dados: texto, imagem, áudio, vídeo etc. Como referencial teórico-metodológico para análise de conteúdo, adotou Bardin (2011) e Saldaña (2016), que se mostram adequados para o cumprimento do objetivo: analisar os desafios dos professores corregentes dos anos iniciais do Ensino Fundamental frente ás tecnologias.

O desenvolvimento da análise de conteúdo se dividiu em três fases segundo Bardin (2011): 1) pré-análise, 2) exploração do material e 3) tratamento dos resultados, inferência e interpretação. 
A primeira, denominada pré-análise, inicia-se com a leitura dos primeiros documentos, formulação de hipóteses e constituição do corpus $^{11}$. Nessa fase, também ocorre a sistematização de ideias preliminares em quatro etapas: a) leitura flutuante, na qual se estabelece o contato com os documentos coletados e se busca um entendimento do material que o pesquisador tem em seu poder; b) escolha dos documentos, que consiste na delimitação do que será analisado; c) formulação das hipóteses e dos objetos, feitos a partir dessas leituras, e também a referenciação dos índices; e d) elaboração de indicadores, envolvendo a determinação de indicadores por meio de recortes de texto nos documentos de análise (Bardin, 2011 p. 126-132).

A segunda fase, exploração do material consiste em recortes - codificação: processo de tratamento dos dados coletados, ou seja, a transformação dos dados brutos em unidades de análise; categorização: processo que comporta o inventário, que isola os elementos, e a classificação, que reparte os elementos e impõe certa organização, tendo como guia critérios previamente estabelecidos e enumeração. Por último, há o tratamento dos resultados, a inferência, na qual ocorre a interpretação dos dados e os resultados são tratados, com a condensação dos dados codificados, buscando as informações para análise, o que resultará nas interpretações inferenciais. É o momento de intuição, de análise reflexiva e crítica (Bardin, 2011).

A importância da contribuição de Saldaña (2016) na pesquisa está na apresentação de dois ciclos de codificação, contendo 31 diferentes possibilidades de composição de códigos, pois a codificação é um processo transitório entre o processo de produção dos dados e a análise extensiva dos dados." (Saldaña, 2016, p. 5, tradução livre).

Segundo o autor (2016, p. 4-9), a codificação é uma técnica exploratória sem fórmulas específicas a serem seguidas, que se vale da designação de códigos (palavras ou pequenas frases) que simbolizem atributos substanciais, evocativos do material coletado. Não se trata de simplesmente colocar rótulos, mas sim um primeiro passo em direção ao encadeamento dos dados com as ideias, e das ideias com os dados. Esse processo cíclico é o que leva à interpretações e análises cada vez mais rigorosas e evocativas.

Por isso, o primeiro ciclo de codificação raramente é o único. São necessárias algumas rodadas de recodificação para que se possa manipular, filtrar, realçar e focalizar

\footnotetext{
${ }^{11} \mathrm{O}$ corpus é o conjunto dos documentos tidos em conta para serem submetidos aos procedimentos analíticos (BARDIN, 2010, p. 122).
} 
aspectos notáveis do material adquirido, a fim de posteriormente gerar categorias, temas, conceitos, alcançar significados, e até construir teorias.

Trata-se de um processo de constante refinação, que parte dos códigos iniciais à formação de categorias que os organizem por alguma característica comum (inclusive pela diferença entre eles). Em seguida, são trabalhadas de maneira que transcendam as particularidades em direção a uma perspectiva temática, conceitual e, eventualmente, teórica. (Saldaña, 2016, p. 8-11).

Antes de realizar o primeiro ciclo de codificação, Saldaña (2016) sugere a realização de uma pré-codificação, com leitura e reflexão dos dados, sublinhando, negritando e circulando todas as palavras e frases que merecem atenção como chaves de evidência para embasar suposições. Já a teoria de elaboração de memórias (memos) diz respeito à pré-codificação, que propõe a construção de questionamentos, análises pessoais e teóricas acerca do que foi destacado como importante na etapa anterior, sondando causas e efeitos.

Após as rodadas de recodificação, focamos nos aspectos notáveis configurando três categorias, tomadas como fatores de desafios dos professores corregentes frente às tecnologias: fatores individuais, institucionais e documentais.

É importante ressaltar que a pesquisadora principal fez a organização dos dados, a estruturação, codificação e categoria de análise e não o software. É fundamental um plano de análise de dados, coerente com base na questão da pesquisa e nas subquestões para permitir a melhor exploração, não apenas dos dados, mas também das ferramentas oferecidas pelo programa.

Na produção dos dados, respeitamos os participantes e seus locais de trabalho de forma a não os colocar em risco de exposição, danos ou perseguição. Evidenciamos, no termo de consentimento, conforme recomenda Creswell (2010), os seguintes aspectos: identificação da pesquisadora, da instituição, motivo da escolha dos participantes e a autorização institucional, propósito, benefícios da pesquisa, riscos, garantia de confidencialidade, possibilidade de se retirar da pesquisa a qualquer momento e nomes dos responsáveis pela pesquisa caso surgissem problemas ou dúvidas.

Após a constituição de dados, lemos e relemos todo o material para captar o sentido do todo, buscando destacar os principais pontos da pesquisa. A análise dos dados se desdobra, primeiramente, no perfil dos participantes delimitados pelo questionário, 
depois apresenta-se a análise das tecnologias empregadas nos documentos oficiais norteadores.

\section{O perfil dos participantes}

O questionário que teve como propósito delimitar o campo de pesquisa, com o retorno de 49 professoras, sendo que duas responderam duplicadamente, computadas então, 47 respostas válidas vindas de 35 escolas municipais, conforme tabela abaixo:

Tabela 1: Participantes da pesquisa

\begin{tabular}{|l|l|l|l|l|l|l|l|l|l|l|c|}
\hline NRES $^{12}$ & BN & BQ & BV & CIC & CJ & MZ & PN & PR & SF & TQ & TOTAL \\
\hline ESCOLAS & 1 & 4 & 5 & 6 & 3 & 3 & 3 & 2 & 6 & 2 & $\mathbf{3 5}$ \\
\hline PROFESSORES & 1 & 7 & 6 & 7 & 4 & 3 & 4 & 3 & 10 & 2 & $\mathbf{4 7}$ \\
\hline
\end{tabular}

As respostas foram exportadas para uma planilha eletrônica do Excel para auxiliar no processo de descrição dos dados.

Formam excluídas 29 respostas, sendo 2 duplicadas; 2 de professoras que não lecionam o componente curricular ciências; 2 de professoras que atuam com o Ensino Fundamental II (6. ${ }^{\circ}$ ao $9 .^{\circ}$ ano), 13 de professoras que não apresentaram disponibilidade para entrevista e em mostrar o caderno de encaminhamento pedagógico e outras 10 de participantes que apresentaram disponibilidade para mostrar o caderno, mas não para a entrevista.

Enviamos um e-mail agradecendo pela disponibilidade e agendando as entrevistas com as 20 professoras que estavam dentro dos critérios de inclusão: atuantes com o componente curricular de Ciências; professores do $1 .^{\circ}$ ao $5 .^{\circ}$ ano; disponibilidade para entrevista e para mostrar o caderno de encaminhamento didático-metodológico. Recebemos o retorno de 13 professoras, confirmando disponibilidade para entrevista.

Com intuito de manter sigilo da identidade de todas, foram utilizados números e letras para identificá-las: letra A para professoras dos 1..$^{\circ}$ anos; B para as dos 2..$^{\circ}$ anos; C para as dos $3 .^{\circ}$ anos; D para as dos $4 .^{\circ}$ anos e F para as dos $5 .^{\circ}$ anos, seguidas dos números de 1 ao 4, de acordo com a quantidade de professoras atuantes no ano. Para estabelecer relação com as escolas em que trabalham, a identificação de cada uma vem seguida da letra

${ }^{12}$ Regionais da Rede Municipal da Educação - BN: Bairro Novo; BQ: Boqueirão; BV: Boa Vista; CIC: Cidade Industrial; CJ: Cajuru; MZ: Matriz; PN: Pinheirinho; PR: Portão; SF: Santa Felicidade; TQ: Tatuquara. 
E (escola). Como há 3 professoras atuantes da mesma escola, foi usada a numeração corresponde a de 1 a 11, de acordo com a escola que atuam, conforme quadro a seguir:

Quadro 2: Legenda professoras e escolas participantes

\begin{tabular}{|c|c|c|c|}
\hline Ano/Turma & Professoras & Escolas & Lê-se \\
\hline 1..$^{\circ}$ ano & A1 & E1 & A1E1 - Professora do $1^{\circ}$ ano, atuante na escola 1 (um) \\
\hline \multirow{4}{*}{$2 .^{\circ}$ ano } & B1 & E1 & B1E1 - Professora do $2^{\circ}$ ano, atuante na escola 1 (um) \\
\hline & $\mathrm{B} 2$ & E2 & B2E2 - Professora do $2^{\circ}$ ano, atuante na escola 2 (dois) \\
\hline & B3 & E3 & B3E3 - Professora do $2^{\circ}$ ano, atuante na escola 3 (três) \\
\hline & B4 & E4 & B4E4 - Professora do $2^{\circ}$ ano, atuante na escola 4 (quatro) \\
\hline \multirow{3}{*}{$3 .^{\circ}$ ano } & $\mathrm{C} 1$ & E5 & C5E5 - Professora do $3^{\circ}$ ano, atuante na escola 5 (cinco) \\
\hline & $\mathrm{C} 2$ & E6 & C2E6 - Professora do $3^{\circ}$ ano, atuante na escola 6 (seis) \\
\hline & $\mathrm{C} 3$ & E7 & C3E7- Professora do $3^{\circ}$ ano, atuante na escola 7 (sete) \\
\hline \multirow{3}{*}{$4^{\circ}$ ano } & D1 & E8 & D1E8 - Professora do $4^{\circ}$ ano, atuante na escola 8 (oito) \\
\hline & D2 & E9 & D2E9 - Professora do $4^{\circ}$ ano, atuante na escola 9 (nove) \\
\hline & D3 & E1 & D3E1 - Professora do $4^{\circ}$ ano, atuante na escola 1 (um) \\
\hline \multirow{2}{*}{$5 .^{\circ}$ ano } & F1 & E10 & F1E10- Professora do $5^{\circ}$ ano, atuante na escola 10 (dez) \\
\hline & $\mathrm{F} 2$ & E11 & F2E11 - Professora do $5^{\circ}$ ano, atuante na escola 11 (onze) \\
\hline
\end{tabular}
Fonte: Loeper e Camargo (2018)

As professoras envolvidas nessa pesquisa responderam que são do gênero feminino e a idade média é de 45 anos. Das participantes, 77\% são formadas em Pedagogia, $15 \%$ em Letras e $8 \%$ em Matemática, sendo que duas apresentam duas formações acadêmicas (uma em direito e outra em Matemática) e duas têm mestrado em Educação. Atuam profissionalmente na RME em média há mais de dez anos, sendo que $61 \%$ atuam entre 10 e 20 anos, $31 \%$ entre 20 e 30 anos e $8 \%$ há menos de 10 anos.

$\mathrm{Na}$ atuação como professoras do componente curricular de ciências temos: entre um e no máximo cinco anos, conforme a Portaria n. ${ }^{\circ}$ 4513, que entrou em vigor em 2013, para organização da docência compartilhada por meio do trio de regência.

Com relação à formação continuada sobre a temática tecnologias, temos $69 \%$ de participação em alguma formação ao longo da vida profissional de cursos ofertados pela própria SME e 55\% de participação em cursos sobre a temática tecnologia ofertados pela SME, o que contribui para prática pedagógica em sala de aula. Com relação à formação continuada referente ao componente curricular ciências, $77 \%$ participaram de alguma formação na própria SME e 39\% consideram que nos cursos já são abordadas as questões sobre as tecnologias.

13 Disponível em: http://multimidia.educacao.curitiba.pr.gov.br/2017/7/pdf/00145041.pdf. Acesso em: 02/02/2017. 


\section{Documentos oficiais norteadores}

Para analisar como a tecnologia está apresentada nos documentos oficiais norteadores dos anos iniciais da Secretaria Municipal da Educação de Curitiba, primeiramente criamos um projeto no Atlas.Ti para cada documento, porém seguimos os mesmos critérios para analisá-los:

a) Volume I e IV do Currículo do Ensino Fundamental.

b) Onze projetos políticos-pedagógicos das escolas participantes.

c) Onze regimentos escolares das escolas participantes.

As etapas prescritas por Bardin (2011) foram realizadas no que se refere, principalmente, à leitura flutuante, à reincidência de palavras e à possibilidade de codificação a priori para iniciar o 1. ${ }^{\circ}$ ciclo de codificação apresentado por Saldaña (2016). Utilizou-se o método de codificação exploratória que, segundo o autor, identifica os atributos preliminares de códigos que posteriormente devem ser refinados.

A partir do método exploratório, aplicou-se uma codificação provisória, com o intuito de identificar no texto onde se localizam a(s) palavra(s) tecnologia(s), baseando-se numa investigação preparatória. Após a identificação do quantitativo, foram codificados e classificados de acordo com a estrutura do documento da RME.

Avançada a reorganização e reanálise dos dados codificados no primeiro ciclo, no 2. ${ }^{\circ}$ ciclo, ocorre o processo de refinamento ou detalhamento do primeiro, fomentando uma reflexão mais profunda sobre o significado dos dados e uma condensação desses dados, de forma mais sistêmica em unidades facilmente analisáveis. Foi aplicada, no segundo ciclo, a codificação teórica para descobrir a categoria central de cada documento (Saldaña, 2016), conforme a síntese de classificação didática das tecnologias, com base em Sancho (1998) e Brito (2006).

\section{A propósito das entrevistas e práticas pedagógicas}

As entrevistas foram agendadas para ocorrer nos horários de permanência ou hora-atividade das professoras, porém não conseguimos realizar todas nas escolas devido à conexão insuficiente com a internet. Somente duas vídeoentrevistas foram realizadas no ambiente escolar, usando o celular e a internet (dados móveis) da própria participante. 
Com as outras 11 participantes, reagendamos o horário para o período noturno em suas residências.

Quadro 3: Vídeoentrevistas

\begin{tabular}{|l|l|l|l|l|l|}
\hline ID & UE & Data & Hora & Aplicativo & Local da vídeo entrevista \\
\hline A1 & E1 & $07 / 11 / 2017$ & $20 \mathrm{~h}$ & appear & residência da professora. \\
\hline B1 & E1 & $06 / 11 / 2017$ & $21 \mathrm{~h}$ & appear & residência da professora. \\
\hline B2 & E2 & $08 / 11 / 2017$ & $19 \mathrm{~h}$ & appear & residência da professora. \\
\hline B3 & E3 & $16 / 11 / 2017$ & $20 \mathrm{~h}$ & appear & residência da professora. \\
\hline B4 & E4 & $10 / 11 / 2017$ & $10 \mathrm{~h}$ & WhatsApp/celular & na escola \\
\hline C1 & E5 & $07 / 11 / 2017$ & $20 \mathrm{~h}$ & appear & residência da professora. \\
\hline C2 & E6 & $18 / 11 / 2017$ & $19 \mathrm{~h}$ & appear & residência da professora. \\
\hline C3 & E7 & $07 / 11 / 2017$ & $21 \mathrm{~h}$ & appear & residência da professora. \\
\hline D1 & E8 & $10 / 11 / 2017$ & $09 \mathrm{~h}$ & WhatsApp/celular & na escola \\
\hline D2 & E9 & $16 / 11 / 2017$ & $17 \mathrm{~h}$ & appear & residência da professora. \\
\hline D3 & E1 & $09 / 11 / 2017$ & $19 \mathrm{~h}$ & appear & residência da professora. \\
\hline F1 & E10 & $28 / 11 / 2017$ & $21 \mathrm{~h}$ & appear & residência da professora. \\
\hline F2 & E11 & $14 / 11 / 2017$ & $19 \mathrm{~h}$ & appear & residência da professora. \\
\hline
\end{tabular}

Fonte: Loeper e Camargo (2018)

$\mathrm{Na}$ entrevista, foi solicitado um planejamento de uma aula em que a professora considerasse que havia integrado o conteúdo curricular trabalhado, o recurso utilizado e o processo de desenvolvimento didático da aula (início/meio/fim). Eles foram recebidos em formato JPG (foto) e transformados em PDF e, com o auxílio do Atlas.Ti, agrupamos e codificamos.

Figura1: Conteúdo das práticas pedagógicas

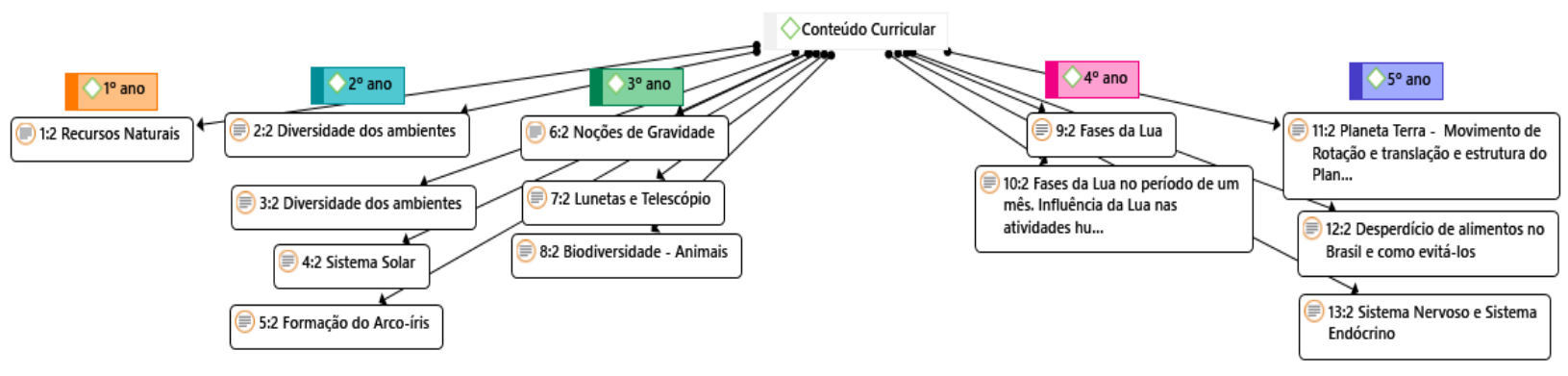

Fonte: Loeper e Camargo (2019)

Para analisar as entrevistas e as práticas pedagógicas, optou-se por utilizar, em linhas gerais, a técnica de codificação de Saldaña (2016). No processo cíclico de levar a interpretações e análises cada vez mais rigorosas, como já vimos na metodologia, o primeiro ciclo de codificação raramente é o único. São necessárias algumas rodadas de recodificação para se focalizar aspectos notáveis do material adquirido, a fim de 
posteriormente gerar categorias, temas, conceitos, alcançar significados, e até construir teorias.

Para o primeiro ciclo de codificação, foi realizado o método elementar que verifica as abordagens primárias para a análise de dados qualitativos. Essa codificação possui filtros básicos, mas focados, para revisar o corpus e criar uma base para futuros ciclos de codificação (Saldaña, 2016).

No método elementar, aplicou-se a codificação in vivo, ou seja, priorizamos "as vozes" das participantes, os códigos, em que surgiram do próprio depoimento ou expressões das participantes, ou seja, um pedaço da quotation como o próprio código, para não perder a essência.

Para a análise de conteúdo dos dados, usamos Bardin (2011) e os ciclos de codificação de Saldaña, conforme quadro abaixo:

Quadro 4: Ciclos de codificação de Saldaña

\begin{tabular}{|c|c|c|}
\hline $\begin{array}{l}\text { CICLO DE COD } \\
\text { ENTREVISTA }\end{array}$ & ALDAÑA (2016) & \\
\hline 1. ${ }^{\circ}$ Ciclo & Método elementar & $\begin{array}{l}\text { Codificação estrutural } \\
\text { Codificação IN VIVO }\end{array}$ \\
\hline Ciclo de transição & Panorama de código & \\
\hline $2 .^{\circ}$ ciclo & Codificação axial & \\
\hline PRÁTICA PEDA & & \\
\hline $1 .^{\circ}$ ciclo & Método elementar & Codificação in vivo \\
\hline 2. ${ }^{\circ}$ ciclo & Codificação Teórica & \\
\hline DOCUMENTOS & RES & \\
\hline 1. ${ }^{\circ}$ ciclo & Método exploratório & Codificação provisória \\
\hline $2 .^{\circ}$ ciclo & Codificação teórica & \\
\hline
\end{tabular}

Em seguida, na análise das transcrições das entrevistas, por meio do ciclo de Saldaña, apresenta-se as três categorias tomadas como fatores dos desafios dos professores corregentes frente às tecnologias: fatores individuais, institucionais e documentais, os quais também foram usados para analisar as práticas pedagógicas.

\section{Resultado e discussões}

\section{Fatores Individuais}

Nas entrevistas, as professoras mencionaram competências e habilidades necessárias ao professor para integração das tecnologias nas práticas pedagógicas. Com o auxílio do Atlas.Ti, foi criada uma lista com palavras das respostas das professoras. 
Aplicou-se Code Landscaping (Panorama de Código), que se baseia na técnica visual de "tags", na qual a palavra ou frase mais frequente de um texto aparece em mais vezes do que as outras. À medida que a frequência de palavras ou frases específicas diminui, o mesmo acontece com o tamanho visual.

A figura 2 corresponde à visualização das palavras mais recorrentes nas entrevistas com relação à competência necessária para integração das tecnologias na prática pedagógica.

Figura 2: Palavras mais recorrentes na entrevista

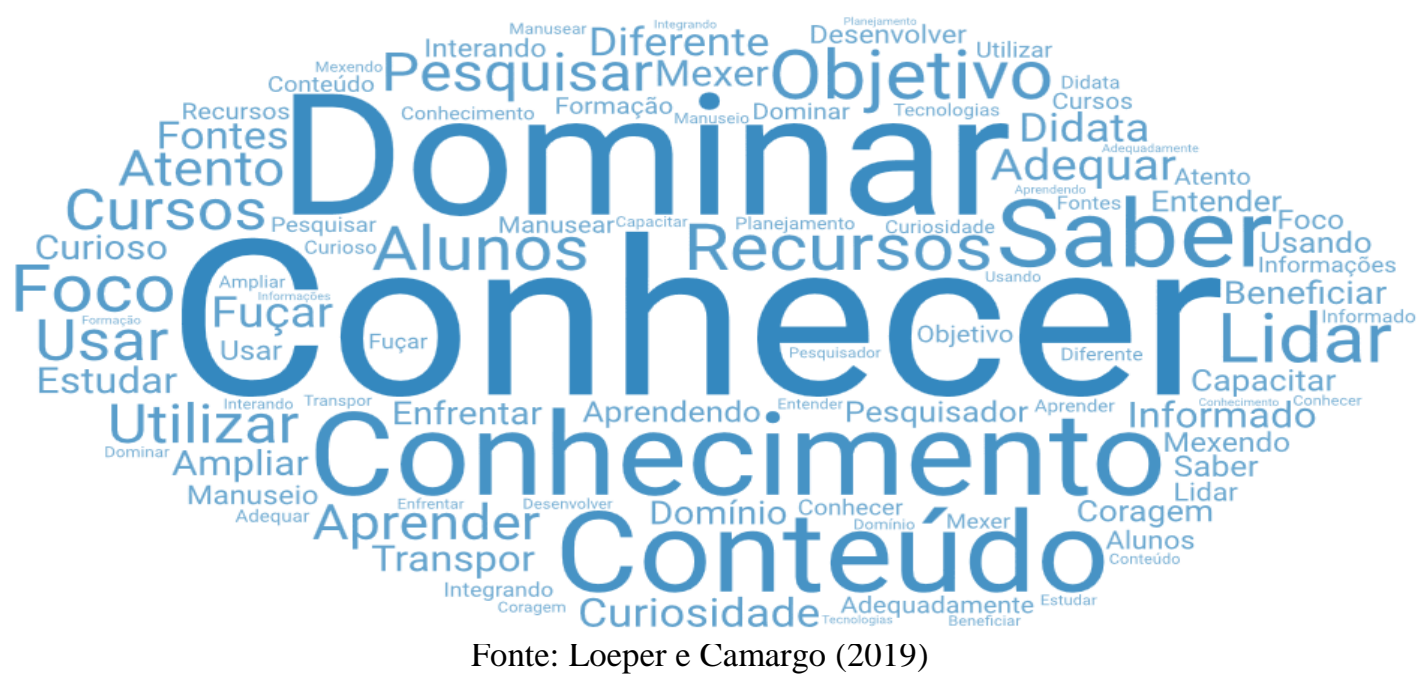

Percebemos a necessidade de realizar o segundo ciclo de codificação para explorar a complexidade das competências, uma forma de avançar na reorganização e reanalisar os dados obtidos no primeiro ciclo. Usamos a codificação axial, que estende o trabalho analítico da codificação inicial, com o objetivo de agrupar estrategicamente os dados que foram "divididos" e reorganizar o conjunto de dados (Saldaña, 2016, p. 109), agrupando as palavras em duas categorias com os mesmos sentidos, segundo as transcrições das entrevistas: Conhecer e Planejar.

\section{Conhecer}

Percebemos que a busca pelo conhecimento é um grande desafio e é visto pelas professoras como uma competência importante para a integração das tecnologias. $\mathrm{O}$ professor precisa ser um pesquisador constante, estar informado e atualizado em relação às tecnologias, para saber como integrá-las no processo de ensino-aprendizagem. Nesse sentido, ele se caracteriza como um "eterno aprendiz" (Demo, 2004), pois a profissão docente requer a constante reconstrução do conhecimento. 
Pelas respostas das professoras, as tecnologias envolvem um saber que vai além do conhecimento técnico da ferramenta, precisam do conhecimento das potencialidades pedagógicas das tecnologias. Porém, percebemos, por meio das práticas pedagógicas, que as professoras têm maior conhecimento e apropriação de tecnologias mais tradicionais, como atividades impressas, imagens, uso do caderno e vídeos.

Analisamos as práticas pedagógica e percebemos que as atividades impressas aparecem $26 \%$ nos planejamentos, o caderno 14\%, o vídeo $25 \%$, aparece em todos os planejamentos, seja para dar início ao conteúdo abordado, ou como mediador para melhor compreensão ou fechamento da aula. As experiências práticas aparecem em $7 \%$ dos planos de aula e em menor quantidade, algumas atividades diferenciadas com a música, o jogo, o planetário, a pesquisa na internet ou o uso do projetor, conforme gráfico abaixo:

\section{Gráfico 1: Tecnologias nas práticas pedagógicas}

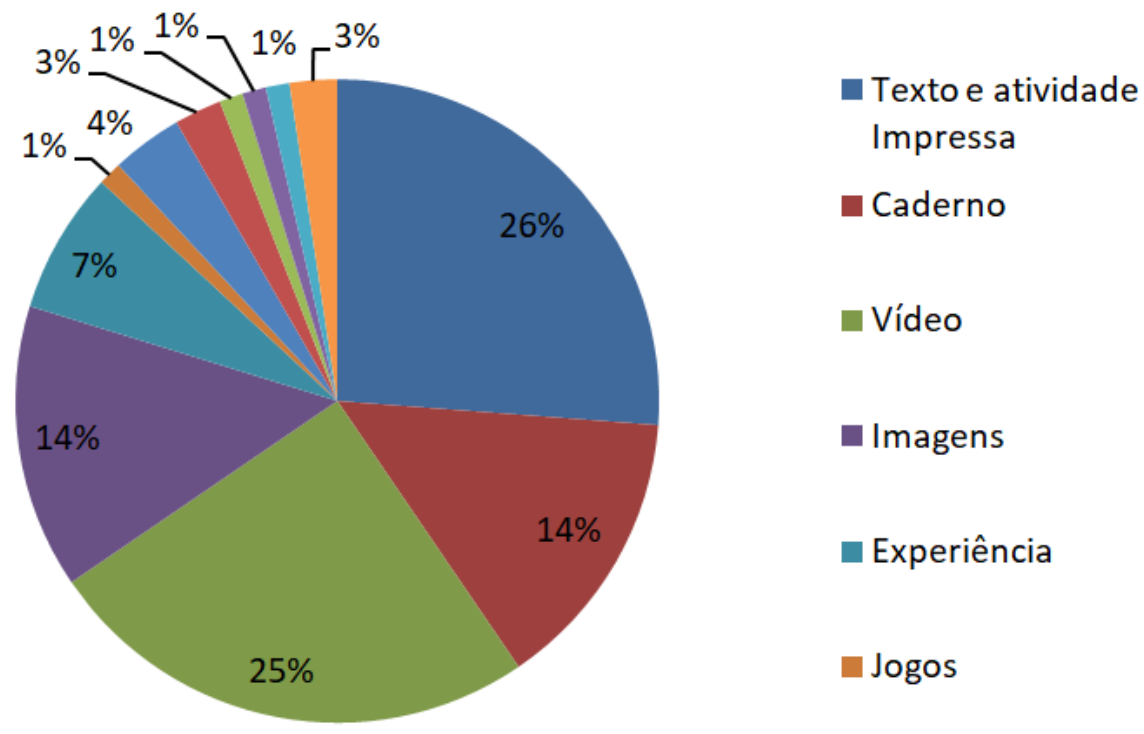

Fonte: Loeper e Camargo (2019)

Conforme o ciclo de apropriação de Camas (2012), é preciso que o professor inove, explore sua prática, que tenha em mente o aprendizado do aluno, de forma a planejar aulas com objetivos claros, utilize a tecnologia para se alcançar o que sem ela não seria possível e dê significado para o seu uso.

Quando se fala de tecnologia integrada à prática pedagógica, há que se pensar não somente na disponibilização de recursos aos estudantes, e sim em propiciar uma prática pedagógica mais enriquecedora e, ao mesmo tempo, integrada e ficou evidente que as participantes desta pesquisa estão no início da adaptação para explorar outras tecnologias, pois as usam para fazer melhor o que já era feito sem elas. 


\section{Planejar}

É importante saber escolher, analisar, selecionar, refletir sobre o propósito do uso da tecnologia para o alcance do objetivo pedagógico proposto. Borba (2014) aborda o termo pensar-com-tecnologia, que está intrinsecamente envolvido com outros aspectos, como elaboração de novas possibilidades ou organização de dinâmicas em sala de aula, entre outros. Ou seja, usar recursos tecnológicos para o processo de ensino-aprendizagem propicia novas formas de aprender, ensinar e produzir conhecimento, de acordo com os propósitos educacionais.

O simples uso da tecnologia em sala de aula não é sinônimo de integração nem de mudança na prática pedagógica. Percebemos que as professoras ainda usam as tecnologias como apoio nas aulas, conforme Camas (2012, p. 55), ainda não há o senso crítico de uso significativo, ou a escolha da melhor ferramenta para um melhor processo educacional, "na transformação e mudança na prática pedagógica”.

\section{Fatores Institucionais}

A questão de infraestrutura inadequada mostrou-se recorrente, tanto de falta de equipamento, manutenção, internet quanto de funcionamento. A infraestrutura inadequada interfere na prática pedagógica, como destaca Moran (2013, p.14), que diz que é preciso: "Uma organização inovadora, aberta, dinâmica, [...] com infraestrutura adequada, atualizada, confortável; tecnologias acessíveis, rápidas e renovadas”. A infraestrutura é, certamente, um dos elementos que influenciam na prática pedagógica do professor e, consequentemente, no uso de recursos tecnológicos conforme a escola precisa de infraestrutura adequada e de constantes investimentos para manutenção e atualização dos recursos tecnológicos. Observamos que, além de investir em equipamentos, o investimento em recursos humanos e no comprometimento também precisa ser considerado para que as professoras integrem as tecnologias em suas práticas, pois as professoras apresentam a necessidade de um profissional capacitado para apoiar e acompanhar o trabalho com tecnologias, com objetivo de minimizar os desafios encontrados.

Outros desafios institucionais abordados foram o tempo pela necessidade de preparar as aulas e organizar os materiais como pontuou a professora A1E1: 
A1E1: É que a ciência é uma aula só por semana, duas horas nem isso dá... então é muito corrido, se você não planeja suas aulas direitinho ela acaba não se realizando e não atinge os objetivos, então a gente procura fazer mais, por conta assim... rápido... para atingir o horário...então o horário é a dificuldade...não posso usar o computador naquele momento, vídeo eu até passo, mas mais do que 25 minutos eu não passo para eles.

E a gestão escolar na valorização dos profissionais que está intimamente relacionada com a profissionalidade (Contreras, 2012), pois se relaciona com os múltiplos aspectos do processo ensino-aprendizagem, como: a valorização do seu pensar, do seu sentir, de suas crenças, de seus valores e não se limita apenas à prática de sala de aula.

\section{Fatores Documentais}

O documento currículo do ensino fundamental aponta as tecnologias como um processo contínuo, pelo qual a humanidade molda e modifica, em que "consideramos a tecnologia como um processo contínuo pelo qual a humanidade cria, transforma e produz materiais, modelos, objetos e ferramentas que modificam a sua qualidade de vida". (Curitiba. 2016, p. 6). Também se apresenta a importância do uso das tecnologias tradicionais: microscópios ópticos e estereoscópicos, lupas, binóculos, bússolas, cronômetros, termômetros e materiais de laboratório; quanto às tecnologias digitais: softwares, simuladores, objetos educacionais digitais, netbooks, tablets, smartphones, projetores multimídia, lousas digitais interativas e a própria internet, com foco pedagógico.

Todas as professoras responderam que o Currículo do Ensino Fundamental, é o documento norteador para o planejamento escolar, porem verificamos que as professoras mencionam apenas os quadros anuais do documento, ou seja somente o conteúdos que tem influenciado diretamente na prática das professoras. “[...] a gente tem o conteúdo, que vem o município de Curitiba e disponibiliza o plano curricular e a gente vai seguindo durante os trimestres, se é igual para todo mundo...E para mim, é tranquilo assim..." (C2E6) ${ }^{14}$

Quanto ao projeto político-pedagógico das escolas participantes 53\% apresentam a tecnologia como organizadora, voltada às formas de organização da escola, e 23\% apontam para a tecnologia social, visando a soluções para uma demanda social. As tecnologias físicas, segundo Brito (2006), estão "relacionadas aos instrumentos físicos, palpáveis" e são apontadas em 14\% dos PPPs, para identificar os instrumentos existentes na escola,

\footnotetext{
14 Com intuito de manter sigilo da identidade das professoras, foram utilizados números e letras para identificá-las: letra A para professoras dos $1 .^{\circ}$ anos; B para as dos $2 .^{\circ}$ anos; C para as dos $3 .^{\circ}$ anos; D para as dos $4 .^{\circ}$ anos e $\mathrm{F}$ para as dos $5 .^{\circ}$ anos, seguidas dos números de 1 ao 4 , de acordo com a quantidade de professoras atuantes no ano. Letra E para as escolas com numeração de 1 a 11.
} 
como: lousa, máquina fotográfica e filmadora digital. As tecnologias simbólicas são apontadas em 4\% dos PPPs, mostrando a importância do sistema de escrita, "apropriação do sistema de escrita alfabético/ortográfico e tecnologias da escrita", e 6\% referem-se a tecnologias educacionais.

Já nos regimentos escolares, observamos que as 11 escolas, usam o modelo enviado pela secretaria municipal às escolas, mudando apenas o nome e modalidade, podemos assim afirmar que no modelo a tecnologia social e a educacional são mencionadas $27 \%$, indicando as tecnologias para um processo educativo diferenciado, com os recursos pedagógicos como possibilidades para oportunizar o contexto educacional e atender às necessidades da sociedade contemporânea. A tecnologia organizadora é mencionada em $20 \%$ e a tecnologia física como simbólica, $13 \%$.

As professoras foram questionadas se os documentos da escola abordam as tecnologias, a maioria das professoras não demonstraram conhecimento relação a elas. Apenas duas professoras responderam que a tecnologia está pontuada no PPP da escola: uma delas, a D3E1, respondeu apenas "sim", mas complementou: "só que assim... elas tão lá, no papel, na teoria”.

As professoras C3E7 e F2E11 acreditam que tecnologia é abordada no PPP da escola, porém, segundo elas, não voltada à prática pedagógica.

F2E11: Eu acho que aborda, só que assim... a aplicação efetiva mesmo em sala de aula, assim, não acontece, e não deve estar la... mas eu acho que o PPP tem lá...tem todo um trabalho voltado para a tecnologia tudo, mas, acho que ainda está por conta da aplicação na prática do professor, que não está ainda natural,...não é utilizado naturalmente no dia a dia, no cotidiano, acho que isso tem uma falha grande ainda.

E seis professoras não souberam responder, justificando que o PPP foi reformulado a pouco tempo e as incertezas nas respostas das outras professoras também demonstraram que não conhecem os documentos, ao afirmarem: "Vi por cima e não vi muita tecnologia" (B1E1), justificando sua resposta ao dizer que o documento já vem pronto: “Também não participei nada assim que eu pudesse dizer: ah devemos focar na tecnologias, isso já vem pronto né, e já vem como usar também....” (B1E1). Ou ainda:

D2E9: O PPP é sempre uma cópia, é um modelo né? Então...eu tenho lá 90\% de quase certeza que sem ter lido o documento que sim, que ele aborda e que ele vai dizer que acontece e que é fundamental e todo discurso acadêmico vai tá lá... do jeito que está nos documentos oficiais, porque é isso que se manda fazer, não é? 
Quanto ao regimento escolar, $80 \%$ das participantes declaram não ter entendimento do documento. Percebemos a necessidade de distanciar o RE da formalidade, da burocracia e apresentar formas participativas e democráticas na sua elaboração e execução, conforme palavras da professora:

F2E11: No regimento interno não tenho... não tenho conhecimento, deveria né? Mas não tenho. A gente deveria ter um momento assim para gente conhecer, mas como eu entrei na escola...é... faz pouco tempo, deveria ter um momento assim para gente ser apresentado a esse regimento interno da escola, mas isso não acontece, em nenhuma reunião pedagógica, nenhum momento assim... antes de uma palestra, que poderia, poderia acontecer né? Mas não acontece.

O Regimento Escolar geralmente é lembrado apenas em situações de indisciplina, porque a parte dos direitos e deveres é a mais divulgada, sendo confundida com o próprio regimento: "regimento interno a gente sabe de algumas regras, aquelas mais básicas." (B3E3).

Compreendemos que os documentos não estão sendo vistos como instrumentos metodológicos elaborados de forma participativa e sim como um modelo pronto e acabado. Veiga (1998, p.23) considera que "por se tratar de um projeto político é importante conhecer as finalidades estabelecidas na legislação em vigor e o que a escola persegue com maior ou menor ênfase".

O desafio, portanto, é exercitar o debate democrático, com diferentes posicionamentos, para construir esses documentos coletivamente e para deixar de ser rol de organização e normas impostas e tornem-se instrumentos consensuais que permeiem as questões disciplinares, administrativas, organizadoras, sociais, e principalmente pedagógicas, como ponto de partida para o processo educativo.

\section{Considerações Finais}

Cada ambiente escolar e professor estabelece uma relação particular com as tecnologias na prática pedagógica, influenciada pelos múltiplos fatores que configuram esse processo e interagem permanentemente com as dimensões: histórica, social, cultural e política. Assim, os fatores que estão em evidência para um determinado professor nem sempre são os mesmos para outros.

A pesquisa analisou os desafios pelos quais os professores corregentes dos anos iniciais do Ensino Fundamental da Rede Municipal de Ensino de Curitiba, passam frente às tecnologias, na atuação do componente curricular de Ciências. 
Para alcançar o objetivo geral foram analisadas como as tecnologias estão apresentadas nos documentos oficiais norteadores dos anos iniciais da Secretaria Municipal da Educação de Curitiba. Bem como identificado os principais desafios dos professores corregentes dos anos iniciais na prática pedagógica do componente curricular de ciências, a partir de três categorias: fatores individuais, institucionais e documentais.

Faz-se necessário relembrar o conceito de tecnologia adotado na pesquisa, vista muito além de equipamentos, ferramentas, aparelhos eletrônicos ou máquinas, são todos os recursos integrados à prática pedagógica, com vistas a melhorar o processo de ensinoaprendizagem.

A escola é um espaço de conflitos, contradições e diferenças, onde são expressadas as relações mais amplas vivenciadas socialmente. A democratização da escola só é possível pela democratização coletiva e participativa das relações sociais como um todo e nesse sentido, observamos que a relação teoria e prática é difusa.

O desafio, portanto, é exercitar o debate democrático, com diferentes posicionamentos, para construir documentos norteadores coletivamente e deixarem de ser rol de organização e normas impostas e tornem-se instrumentos consensuais que permeiem as questões disciplinares, administrativas, organizadoras, sociais, e principalmente pedagógicas, como ponto de partida para o processo educativo. Enfim, o desafio está em conceber esses documentos e praticá-los para além do registro e da organização de normas.

Nos fatores documentais os documentos oficiais norteadores, defendem a utilização de tecnologias articulada aos encaminhamentos da aula, de maneira integrada aos conteúdos para além de meros equipamentos, apontam a importância do acesso às tecnologias no ambiente escolar como condição principal para promover a sensibilização dos profissionais quanto ao uso desses recursos em sala de aula. Porém neste quesito, percebeu-se a maioria dos professores não tem conhecimento dos documentos norteadores, principalmente do Projeto Político Pedagógico e do Regimento Escolar.

No entendimento das professoras pesquisadas os documentos são somente um rol de conteúdos e regras, cuja elaboração não participaram, ficando restrito à gestão escolar ou equipe técnica. Porém podemos afirmar pela pesquisa realizada que o currículo prescrito tem influenciado diretamente nas práticas dos professores.

Nos fatores individuais, as práticas pedagógicas analisadas no que se refere às tecnologias foi perceptível que estas aparecem como suporte/apoio, bem como ainda não 
há o senso crítico de uso significativo, da escolha da melhor ferramenta para um melhor processo educacional, "na transformação e mudança na prática pedagógica". (Camas, 2012, p. 55).

E nos fatores institucionais as escolas ainda apresentaram uma infraestrutura inadequada e desatualizada para que ocorra essa mudança efetivamente.

Nesse contexto, verificamos que, mesmo vivenciando tempos de mudanças e desafios cotidianos, o professor, como agente transformador influenciado por esse movimento, enfrenta e enfrentará muitos desafios individuais, institucionais e documentais se quiserem acompanhar esse processo e se atualizar, inovar e aprimorar a sua prática pedagógica frente às tecnologias.

Há que se pensar não somente na disponibilização de recursos, técnicas ou materiais. E sim, refletir sobre os diferentes espaços e tempos da sociedade, as diversas invenções, quais recursos estão disponíveis, que uso pode-se fazer e quais outros recursos poderiam ser implementados para propiciar uma prática pedagógica mais enriquecedora e, ao mesmo tempo, integrada.

Futuras pesquisa, nesse sentido, podem aprofundar o papel da gestão escolar nas esferas de incentivo em projetos envolvendo tecnologias, para a formação continuada e nos processos de gestão democrática no ambiente escolar. Aprofundar os fatores: Individuais: o professor corregente e a interdisciplinariedade; Institucionais: o papel da gestão escolar nas esferas de incentivo em projetos envolvendo tecnologias; e nas esferas democráticas e participativas; Documentais: a importância da participação dos professores na relação da teoria e prática.

\section{Referências}

Bardin, L. (2011). Análise de conteúdo. Edições 70.

Brasil. (1998). Parâmetros Curriculares Nacionais: Ciências Naturais. Secretaria de Educação Fundamental. MEC/SEF.

Brito, G. S. (2006). Inclusão digital do profissional professor: entendendo o conceito de tecnologia. Artigo apresentado no $30^{\circ}$ Encontro Anual da ANPOCS.

Camas, N. P. V. (2008). Origens e evolução de um periódico científico eletrônico na área de educação e currículo construído na colaboração pedagógica. Revista eCurriculum: Pontifícia Universidade Católica de São Paulo. 
Camas, N. P. V. (2012) A literacia da informação na formação de professores. In: (Org.). Tecendo fios na educação: da informação nas redes à construção do conhecimento mediada pelo professor. Curitiba.

Constituição da República Federativa do Brasil (1988). Senado.

Comitê Gestor da Internet no Brasil (2016). O uso das tecnologias de informação $e$ comunicação nos equipamentos culturais brasileiros [Versão Eletrônica]. https://www.cgi.br/media/docs/publicacoes/2/TIC_CULT_2016_livro_eletronico.pdf

Contreras, J. (2012). A autonomia de professores. 2. ed. Cortez

Curitiba. (2016). Prefeitura Municipal. Secretaria Municipal da Educação. Currículo do ensino fundamental. 5 v. [Versão Eletrônica] https://educacao.curitiba.pr.gov.br/

Creswell, J. W. (2010). Projeto de pesquisa: métodos qualitativo, quantitativo e misto. 3. ed. Artmed.

Delizoicov, N. C., \& Slongo, I. I. P. (2011). O ensino de ciências nos anos iniciais do Ensino Fundamental: elementos para uma reflexão sobre a prática pedagógica. Série-Estudos: n. 32. Campo Grande, MS.

Fracalanza, H., Amaral, I.A., \& Gouveia, M.S.F. (1986). O ensino de ciências no primeiro grau. Atual.

Fumagalli, L. (1998). O ensino de ciências naturais no nível fundamental da educação formal. In: Weissmann, H (Org). Didática das ciências naturais: contribuições e reflexões. Porto Alegre: ArtMed.

Loeper. J. G. (2019). As tecnologias no ensino de ciências: os desafios dos professores corregentes dos anos iniciais. Dissertação - Universidade Federal do Paraná, Curitiba.

Lüdke, M., \& André, M. (1986). Pesquisa em educação: abordagens qualitativas. São Paulo: EPU.

Moran, J. M. A. (2013). Educação que desejamos: novos desafios e como chegar lá. 5.d. Papirus.

Preti. D. (1994). Análise de histórias orais. Humanitas Publicações.

Kenski, V. M. (2007). Educação e tecnologias: o novo ritmo da informação. 4 ed. Papirus.

Ringstaff, C., Dwyer, D. C. \& Sandholtz, J. H. (1997). Ensinando com tecnologia: criando salas de aula Centradas nos alunos. ArtMed.

Saldaña, J. (2016). The coding manual for qualitative researchers. Sage.

Sancho, J. M. (1998). Para uma tecnologia educacional. Artmed.

Simonian, D. M. (2018). Desenvolvimento profissional do pedagogo escolar entre ausências e invisibilidade: perspectivas de saberes para a articulação das das tecnologias na cultura escolar. Tese (Doutorado em Educação) - Universidade Federal do Paraná, Setor de Educação, Curitiba.

Vasconcellos, C. dos S. (2006). Planejamento: projeto de ensino aprendizagem e projeto político-pedagógico: elementos metodológicos para elaboração e realização. 16 . ed. Libertad.

Veiga, I. P. (1998). Projeto político-pedagógico da escola: uma construção possível. Papirus. 
Veiga, I. P. A. (2006). Técnicas de ensino: novos tempos, novas configurações. Papirus.

Autores

Juciele Gemin Loepe

Doutoranda do programa de pós-graduação em Educação em Ciências e Matemática (PPGECM-UFPR). Participante do Grupo de Pesquisa em Ensino e Aprendizagem de

Ciências e Matemática (GPEACM-UFPR). E-mail: jgloeper@gmail.com

Sérgio Camargo

Doutor em Educação para a Ciência pela Universidade Estadual Paulista "Júlio de Mesquita Filho" (UNESP), com tese sobre formação de professores de Física. Professor do

Departamento de Teoria e Prática de Ensino do Setor de Educação da Universidade Federal do Paraná (UFPR) e do Programa de Pós-graduação em Educação em Ciências e

em Matemática da UFPR. É um dos líderes do Grupo de Pesquisa em Ensino e Aprendizagem de Ciências e Matemática, com interesse em temas relacionados ao ensino de Ciências, particularmente no Ensino de Física, em questões relacionadas ao Ensino, à Aprendizagem e à formação inicial e contínua de professores. E-mail: s1.camargo@gmail.com 